\title{
Midline Lumbar Fusion for Patients with Adjacent Segmental Disease after Posterior Lumbar Interbody Fusion: A Comparative Study between Midline Lumbar Fusion and Posterior Lumbar Interbody Fusion
}

\author{
Corresponding author: \\ Sang Hyun Kim \\ Department of Neurosurgery, \\ Ajou University Hospital, Ajou \\ University School of Medicine, \\ 164, World Cup-ro, Yeongtong-gu, \\ Suwon 16499, Republic of Korea \\ Tel: +82-31-219-5230 \\ Fax: +82-31-219-5238 \\ E-mail: shkim709@aumc.ac.kr
}

Geon Woo Oh, Sang Hyun Kim

Department of Neurosurgery, Ajou University Hospital, Ajou University School of Medicine, Suwon, Republic of Korea

Received: August 11, 2017

Revised: September 4, 2017

Accepted: September 5, 2017
Objective: This study is a comparative analysis for the radiologic and clinical outcomes of midline lumbar fusion (MIDLF) and posterior lumbar interbody fusion (PLIF) in patients with adjacent segmental disease (ASD) after PLF. Methods: Thirty patients who met the inclusion criteria were targeted. Of those 30 patients, 10 underwent MIDLF and 20 underwent PLF. Preoperative and postoperative radiologic outcomes for bone fusion and clinical outcomes for blood loss, operation time and visual analog scale for pain relief were evaluated between the two groups. Postoperative bone fusion status was measured using a 6-point scoring system. Results: Bone fusion was successfully achieved in both groups. The MIDLF group had significantly less blood loss during the operation and shorter operation times than those in the PLIF group $(p<0.05)$. There was a statistically significant interaction between group and time in the mean level of axial pain $(p<0.05)$. Compared to before surgery, axial pain improved in both groups at each postoperative follow up. MIDLF was significantly more effective in the relief of axial pain than PUF at every postoperative follow up $(p<0.05)$. Conclusion: MIDLF was as effective as PLIF in bone fusion and relief of postoperative axial pain. MIDLF may be a good alternative in patients with ASD after PLIF.

Key Words: Laminectomy; Lumbar vertebrae; Spinal fusion

\section{INTRODUCTION}

Several types of lumbar fusion techniques have been used in patients with degenerative spinal disease. Midline lumbar fusion (MIDLF) has emerged among the new lumbar fusion techniques developed in recent years ${ }^{22,27)}$. It is important for surgeons to select the appropriate technique to avoid postoperative complications, especially because various techniques are readily available for lumbar fusion surgery.

Adjacent segmental disease (ASD) is a degenerative disease with mechanical dysfunction that occurs at the contiguous spinal level after spinal surgery ${ }^{14,25)}$. For the cervical spine, approximately $7 \%$ to $9 \%$ of patients with ASD require additional surgery ${ }^{13,19)}$. For the lumbar spine, approximately $14 \%$ to $37 \%$ of patients with ASD require additional surgery ${ }^{8,11)}$.

There are various hypotheses for the occurrence of ASD. Anatomical deformity, increasing intradiscal pressure, sagittal imbalance and increased biomechanical demands have been proposed as etiological factors for $\mathrm{ASD}^{1,5,9,14)}$. Spinal instability due to the removal of bone and ligamentous structure during spinal surgery is another potential cause of $\mathrm{ASD}^{4}$.
Sometimes, ASD occurs as a complication following lumbar fusion surgery ${ }^{7}$. More studies are needed to evaluate the surgical outcomes of MIDLF in patients with ASD since MIDLF was just recently developed. We conducted a comparative study of the radiologic and clinical outcomes between MIDLF and posterior lumbar interbody fusion (PLIF) in patients with ASD after PLIF in order to confirm whether MIDLF is an effective and alternative surgical option in patients with ASD after PLIF.

Among the patients with ASD after PLIF, we focused on those who underwent additional lumbar fusion surgery. We separated this study's participants into two groups. One group underwent an operation with PLIF and the other group underwent an operation with MIDLF. Through a comparative analysis of the clinical outcomes for each group, we evaluated the utility of the MIDLF surgical technique in patients with ASD after PLIF.

\section{MATERIALS AND METHODS}

\section{Patient Population}

This study had a retrospective design that targeted patients 
who underwent additional lumbar fusion surgery with ASD after PLIF at our hospital between December 2014 and January 2016. After receiving Institutional Review Board approval, we started an investigation based on electronic medical records and radiographic data. The inclusion criteria were as follows: (1) postoperative ASD after PLIF; (2) recurrent lasting pain in the lower back and lower limbs after a minimum of 6 months of conservative treatment after PLIF; and (3) available postoperative radiographic data for at least 12 months. Of the 30 patients who met the inclusion criteria, 10 underwent MIDLF and 20 underwent PLIF. MIDLF was performed on patients who had enough remaining pedicle space to allow for additional screw insertion at the same pedicle as the previous screw insertion. PLIF was performed on patients who did not meet the criteria for MIDLF. Of the 10 patients who underwent MIDLF, 9 patients and 1 patient underwent lumbar fusion surgery of the spine for levels 1 and 2, respectively. Among the 20 patients who underwent PLIF, 15 and 5 patients underwent lumbar fusion surgery of the spine for levels 1 and 2 , respectively.

\section{Surgical Technique}

A midline incision was made on the surgical levels and the spinous process was removed to ensure proper angulation. Screws were inserted through the specialized trajectory path in the sagittal and axial plane for the MIDLF operation. Careful dissection and exposure proceeded to prevent fractures of the pars interarticularis and medical wall of the pedicle ${ }^{22,27}$. Lumbar interbody fusion was identically performed on both groups. Autologous local bone chips were inserted into the disc space after a discectomy and were compacted with a bone impactor. Two polyetheretherketone (PEEK) cages packed with autologous bone chips were inserted into the disc space after compaction of the bone chips. A novel cortical bone trajectory (CBT) screw fixation was performed in the pedicle's medial and caudal points with anterior-posterior imaging under $\mathrm{C}$-arm guidance after a microsurgical laminectomy and lumbar interbody fusion. Upper pedicle screws were inserted in an upward and lateral direction of the disc space, and lower pedicle screws were inserted in downward and lateral direction of the disc space. Pedicle screw insertion was performed in a traditional manner for PLIF operations ${ }^{6}$. Upper and lower pedicle screws were inserted in a parallel and inward direction of the disc space.

\section{Radiographic Evaluations \& Clinical Outcomes}

Preoperative and postoperative radiographic evaluations and clinical outcomes were compared between the two groups. All patients were followed for postoperative data collection at 3, 6, and 12 months using a serial anteroposterior and lateral plain radiographs. Lateral flexion-extension radiography and computed tomography (CT) scans were obtained at the 12-month postoperative follow up to evaluate bone fusion status. There are many analyses for spinal instability ${ }^{3,12,16,30)}$. A stable spine was defined as no or less than $2 \mathrm{~mm}$ translation and no angulation in the flexion-extension radiographs of patients. Postoperative bone fusion status was measured using a 6-point scoring system as an indicator of bone fusion ${ }^{17}$. The criteria included bridging bone formed on more than two of six sides (i.e., anterior, posterior, superior, inferior, and both lateral sides around the PEEK cages), as determined by the CT scan images performed at 12 months after lumbar fusion surgery. Blood loss during the operation and operation time were checked for each group. The authors used the visual analog scale (VAS) score for pain relief assessment before and after surgery. The VAS score for axial pain and radiating pain was examined before surgery and at 1, 6, and 12 months after surgery. The mean VAS scores for each group were compared at each time period.

\section{Statistical Analysis}

Statistical analyses were performed using the Statistical Package for the Social Sciences, version 23.0 software (SPSS Inc., Chicago, IL, USA). Data are presented as means and standard deviations. Nonparametric tests were used because the data was not normally distributed. Sex and spine level were analyzed by the Fisher exact test. Age, postoperative bone fusion status, blood loss during the operation, and operation time were analyzed by the Mann-Whitney U test. The differences between the VAS scores for axial pain and radiating pain before surgery and at 1, 6, and 12 months after surgery in each group were analyzed by mixed models for repeated measures. Statistical significance was considered when the p-value was less than 0.05 .

\section{RESULTS}

The postoperative 1-year follow-up plain X-ray images demonstrated spinal stability in both groups compared with the preoperative X-ray images (Figs. 1, 2). The formation of the bridging bone in each group was apparent on the postoperative 12-month follow up CT scan images (Figs. 3, 4). There was not a statistically significant relationship between the two groups in terms of age, sex, and level of the spine $(\mathrm{p}>0.05)$ (Table 1). The bone fusion statuses are shown in Table 2. The mean score for the bone fusion rate around PEEK cages was over 5 points (on a 6-point scoring scale) in all patients $^{177}$. Successful bone fusion was achieved in both groups. There was not a statistically significant difference between the two groups in terms of bone fusion ( $>0.05$ ) (Table 2). There were no or less than $2 \mathrm{~mm}$ translation and no angulation in the postoperative flexion-extension radiographs of patients in both groups.

On average, the MIDLF group had significantly less blood loss during the operation and significantly shorter operation 

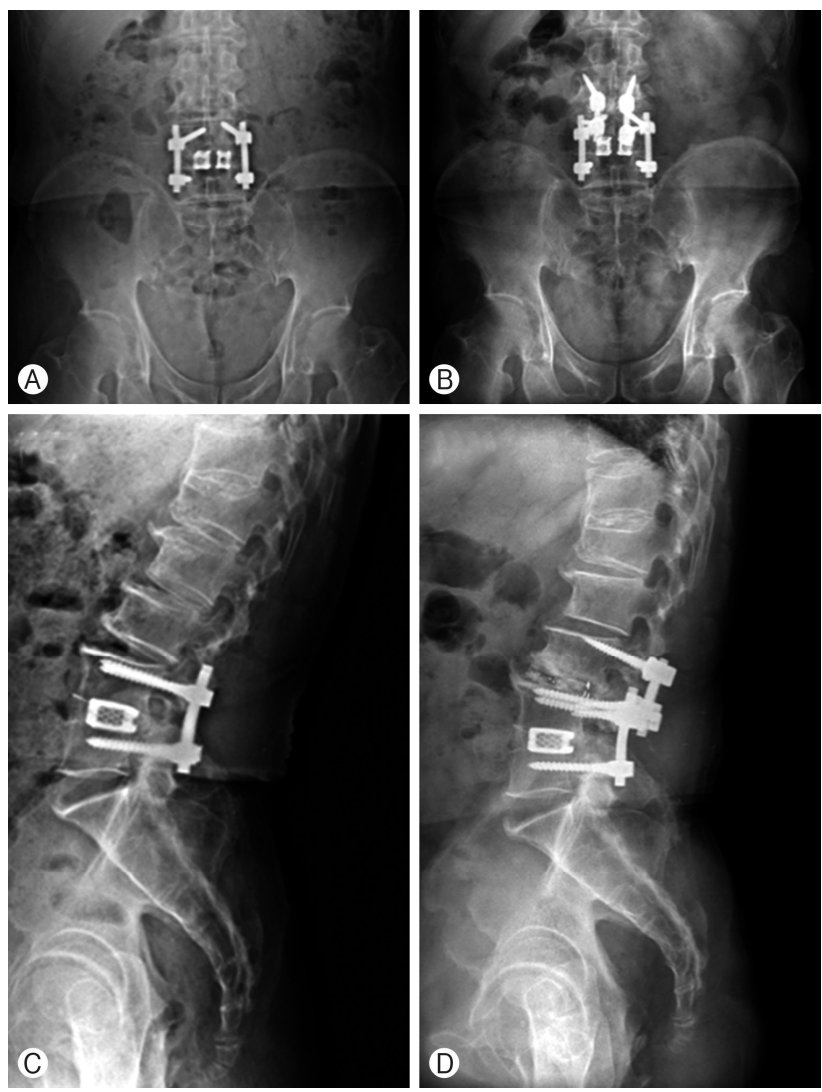

Fig. 1. Comparison between L-spine X-ray images before and after midline lumbar fusion in patients with adjacent segmental disease after posterior lumbar interbody fusion. L-spine X-ray anterior-posterior view and lateral view (A, C) before surgery and L-spine X-ray anterior-posterior view and lateral view (B, D) after surgery are shown.

Table 1. Comparison of the demographic data between two groups

\begin{tabular}{lcrr}
\hline \hline Variable & MIDLF $(n=10)$ & PLIF $(n=20)$ & $p$-value \\
\hline Age & $61.40 \pm 12.12$ & $62.40 \pm 9.29$ & 1.0000 \\
Sex & & & 0.6904 \\
$\quad$ Male & $4(40 \%)$ & $6(30 \%)$ & \\
$\quad$ Female & $6(60 \%)$ & $14(70 \%)$ & \\
Levels of the spine & & & 0.6328 \\
$\quad 1$ level & $9(90 \%)$ & $15(75 \%)$ & \\
2 level & $1(10 \%)$ & $5(25 \%)$ & \\
\hline
\end{tabular}

The data is presented as mean \pm standard deviation or number (\%). The Mann-Whitney $U$ test and the Fisher's exact test were used to calculate the p-values.

MIDLF: midline lumbar fusion; PLIF: posterior lumbar interbody fusion.

time than those in the PLIF group $(\mathrm{p}<0.05)$ (Table 2). This finding suggests that MIDLF may be better than PLIF for blood loss and operation time.

There was a statistically significant relationship between both groups at every postoperative time (preoperative, postoperative
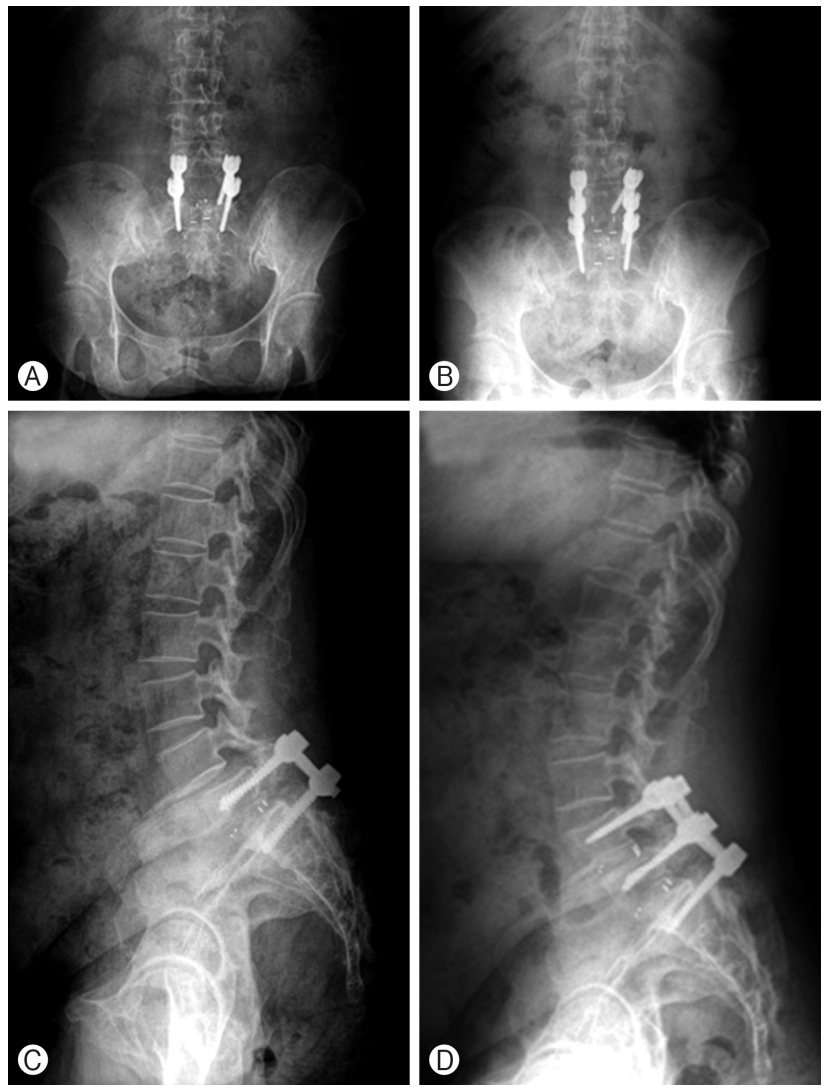

Fig. 2. Comparison between the L-spine $X$-ray images before and after posterior lumbar interbody fusion (PLIF) in patients with adjacent segmental disease after PLIF. L-spine X-ray anterior-posterior view and lateral view $(A, C)$ before surgery and L-spine $X$-ray anterior-posterior view and lateral view $(B, D)$ after surgery are shown.
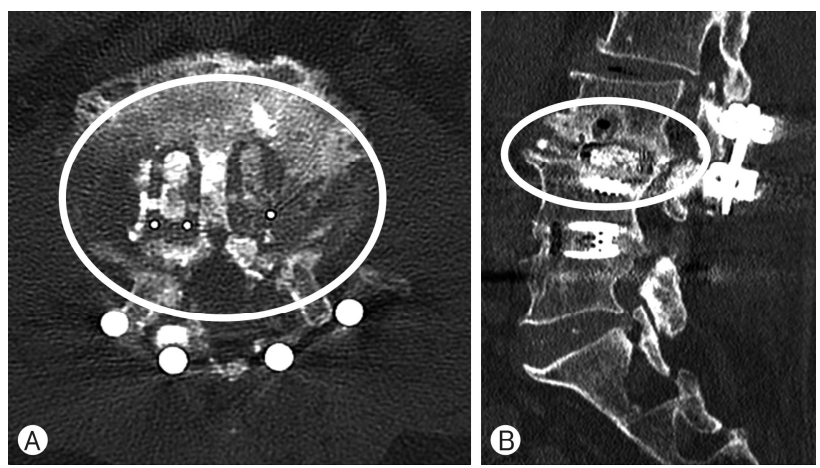

Fig. 3. The postoperative 12-month follow up axial (A) and sagittal (B) computed tomography scan images exhibit the formation of a bridging bone after midline lumbar fusion in patients with adjacent segmental disease after posterior lumbar interbody fusion.

1-, 6-, and 12-months after surgery) in mean axial pain $(\mathrm{p}<0.05)$ (Table 3). MIDLF was significantly more effective in axial pain relief than PLIF at every postoperative time $(\mathrm{p}<0.05)$ (Table 3 , Fig. 5).

There was no statistically significant difference between the 

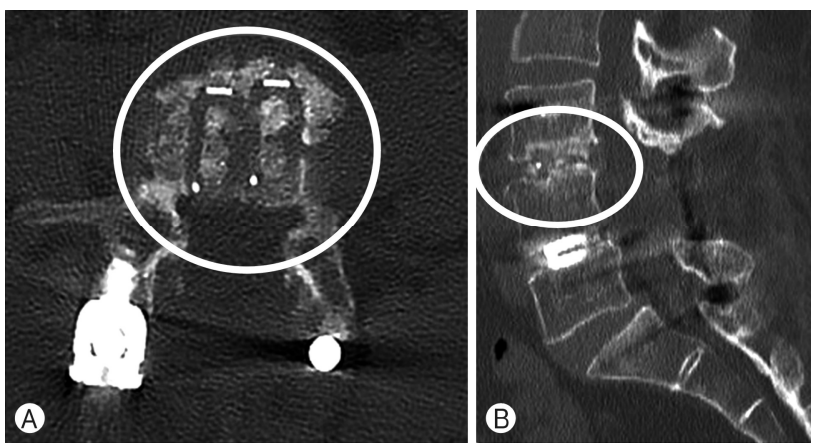

Fig. 4. The postoperative 12-month follow up axial (A) and sagittal (B) computed tomography scan images demonstrate the formation of the bridging bone after posterior lumbar interbody fusion (PLIF) in patients with adjacent segmental disease after PLIF.

Table 2. Postoperative comparisons of the radiologic and clinical evaluations between the two groups

\begin{tabular}{lccc}
\hline \hline Variable & MIDLF $(n=10)$ & $P L I F(n=20)$ & $p$-value \\
\hline Bone fusion status* & $5.85 \pm 0.34$ & $5.55 \pm 0.56$ & 0.0864 \\
Loss of blood (cc) & $300 \pm 216.03$ & $747.50 \pm 689.68$ & 0.0171 \\
Surgery time (min) & $153.50 \pm 43.47$ & $240.00 \pm 68.15$ & 0.0018 \\
\hline
\end{tabular}

The data is presented as mean \pm standard deviation.

The Mann-Whitney $U$ test was used to calculate the p-values.

*No. of bridging bones formed around the polyetheretherketone cages.

MIDLF: midline lumbar fusion; PLIF: posterior lumbar interbody fusion.

Table 3. P-values for the differences in the visual analog scale score for axial pain and radiating pain between before surgery, and at 1, 6, and 12 months after surgery in each group

\begin{tabular}{lcc}
\hline \hline & $\begin{array}{c}\text { p-value for } \\
\text { mean axial } \\
\text { pain }\end{array}$ & $\begin{array}{c}\text { p-value for } \\
\text { mean radiating } \\
\text { pain }\end{array}$ \\
\hline Correlation with each of groups & 0.0258 & 0.0675 \\
Correlation with each of times & $<0.001$ & $<0.001$ \\
Correlation between each of & 0.0312 & 0.0839 \\
groups and each of times & & \\
\hline
\end{tabular}

Mixed models for repeated measures were used to calculate the p-values.

two groups in mean radiating pain ( $\mathrm{p}>0.05$ ) (Table 3). The level of radiating pain improved in both groups at each postoperative time (Fig. 6).

\section{DISCUSSION}

The incidence of ASD after lumbar fusion varies across many studies $^{23)}$. Risk factors for ASD include preoperative disc degeneration, postoperative sagittal imbalance and more ${ }^{2,20)}$. Patients who undergo open or minimally invasive instrumented

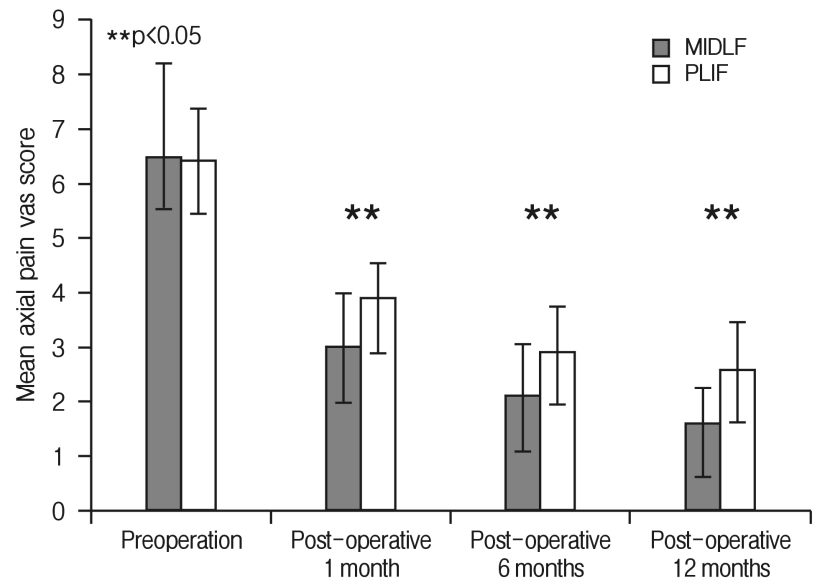

Fig. 5. Comparison of the mean axial pain visual analog scale scores in the each group between any particular moment before surgery and at 1, 6, and 12 months after surgery (mean \pm standard deviation). There was a statistically significant association for both groups at every postoperative time $(p<0.05)($ Table 3$)$. This was analyzed by a mixed model for repeated measure analysis. MIDLF: midline lumbar fusion; PLIF: posterior lumbar interbody fusion.

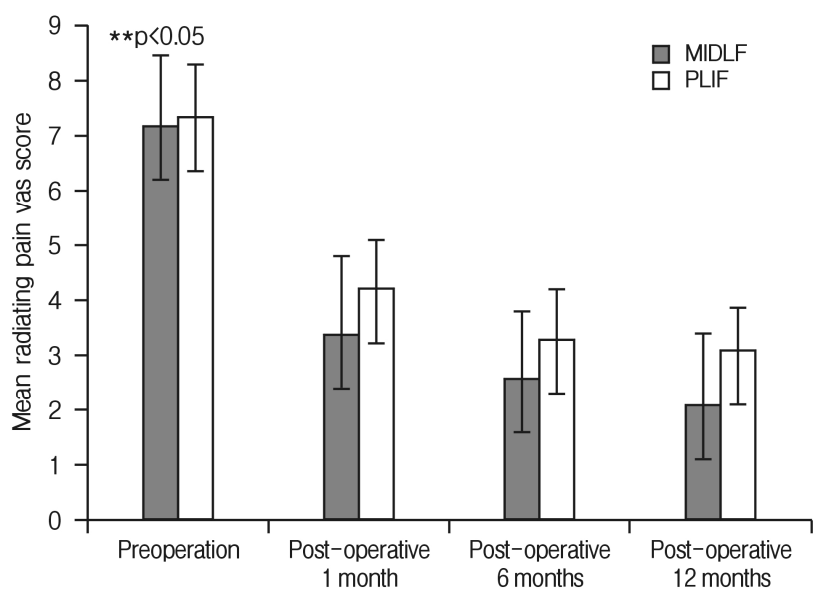

Fig. 6. Comparison of the mean radiating pain visual analog scale scores in each group between before surgery and at 1,6 , and 12 months after surgery (mean \pm standard deviation). There was not a statistically significant association for both groups at every postoperative time ( $p>0.05)$ (Table 3). This was analyzed by a mixed model for repeated measure analysis. MIDLF: midline lumbar fusion; PLIF: posterior lumbar interbody fusion.

lumbar fusion surgery are more likely to develop ASD after surgery than patients who undergo non-instrumented fusion ${ }^{7}$.

PLIF has been widely performed on patients. However, there are several complications that can arise from PLIF, including screw misplacement ${ }^{10,18)}$ and screw loosening ${ }^{29)}$. Such complications can occur during screw insertion into the medullary bone, especially in patients with osteoporosis ${ }^{27}$. None of the participants in this study reported complications.

MIDLF is composed of a posterior midline approach, micro- 
surgical laminectomy, and CBT screw fixation ${ }^{27)}$. CBT screw fixation has several advantages to include: (1) The CBT is considered less invasive than the traditional screw trajectory; (2) The CBT approach may reduce injury or trauma to the neurovascular structures in close proximity to the pedicle; (3) The CBT may also avoid injury to the medial branch nerves, which arise from the dorsal rami of each lumbar spinal nerve $e^{24)}$. It has been reported that MIDLF results in less damage to the multifidus muscle compared to PLIF ${ }^{15)}$.

MIDLF does not invariably produce good progress. Vertebral slip and facet degeneration, which occurs in $11.8 \%$ of patients, are related to facet joint violation after $\mathrm{MIDLF}^{21)}$. Complications, such as screw loosening ${ }^{26)}$ and epidural hematoma ${ }^{28)}$, can also occur. Such complications were not evidenced in this study. While performing the surgery, it was necessary to check the exact trajectory using video equipment, which was CT or a $\mathrm{C}-\mathrm{rm}$, before and during the operation to reduce the risk for such postoperative complications.

The radiologic and clinical outcomes between MIDLF and PLIF groups in the patients with ASD after PLIF were compared. The bone fusion was successful in both groups at 12 months after surgery. This outcome contributes to the improvement in stability for both groups.

There was a statistically significant difference in blood loss and operation time between the MIDLF and PLIF groups $(\mathrm{p}<0.05)$ (Table 2); MIDLF involved less blood loss and shorter operation times compared to PLIF. However, PLIF was performed more frequently at level 2 than MIDLF (mean MIDLF level =1.1, mean PLIF level=1.25). The former results might be explained by the higher number of participants in the PLIF group that required higher operation levels, which may be associated with more blood loss and longer operation times. More studies are needed to prove that MIDLF is indeed better than PLIF in terns of blood loss and operation time.

Both MIDLF and PLIF separately contributed to pain relief at each postoperative time. MIDLF provided significantly better axial pain relief than PLIF at every postoperative time $(\mathrm{p}<0.05)$. At the same time, there was not a statistically significant relationship between groups and times in radiating pain $(\mathrm{p}>0.05)$ (Table 3). The size of the incision site of MIDLF, which is relatively smaller than that of PLIF, might explain why MIDLF is superior to PLIF in axial pain relief.

The limitations of this study are a small sample size and short follow-up period. It is necessary to collect data across more cases and include a longer follow-up period to overcome these limitations. Other considerations include the subjectivity of the VAS scores and selection bias.

\section{CONCLUSION}

Both MIDLF and PLIF can be used in the patients with ASD after a posterior lumbar fusion. MIDLF was as effective as PLIF in bone fusion. In addition, MIDLF was more effective in axial pain relief than PLIF. MIDLF may be a good alternative surgical option in patients with ASD after PLIF.

\section{CONFLICTS OF INTEREST}

No potential conflict of interest relevant to this article was reported.

\section{REFERENCES}

1. Anakwenze OA, Auerbach JD, Milby AH, Lonner BS, Balderston RA: Sagittal cervical alignment after cervical disc arthroplasty and anterior cervical discectomy and fusion: results of a prospective, randomized, controlled trial. Spine (Phila Pa 1976) 34: 2001-2007, 2009

2. Anandjiwala J, Seo JY, Ha KY, Oh IS, Shin DC: Adjacent segment degeneration after instrumented posterolateral lumbar fusion: a prospective cohort study with a minimum five-year follow-up. Eur Spine J 20:1951-1960, 2011

3. Baeesa SS, Medrano BG, Noriega DC: Long-term outcomes of posterior lumbar interbody fusion using stand-alone ray threaded cage for degenerative disk disease: a 20-year follow-up. Asian Spine J 10:1100-1105, 2016

4. Cardoso MJ, Dmitriev AE, Helgeson M, Lehman RA, Kuklo TR, Rosner MK: Does superior-segment facet violation or laminectomy destabilize the adjacent level in lumbar transpedicular fixation? An in vitro human cadaveric assessment. Spine (Phila Pa 1976) 33:2868-2873, 2008

5. Chang UK, Kim DH, Lee MC, Willenberg R, Kim SH, Lim J: Changes in adjacent-level disc pressure and facet joint force after cervical arthroplasty compared with cervical discectomy and fusion. J Neurosurg Spine 7:33-39, 2007

6. Cloward RB: The treatment of ruptured lumbar intervertebral discs by vertebral body fusion. I. Indications, operative technique, after care. J Neurosurg 10:154-168, 1953

7. Epstein NE: Adjacent level disease following lumbar spine surgery: A review. Surg Neurol Int 6:S591-S599, 2015

8. Etebar S, Cahill DW: Risk factors for adjacent-segment failure following lumbar fixation with rigid instrumentation for degenerative instability. J Neurosurg 90:163-169, 1999

9. Finn MA, Brodke DS, Daubs M, Patel A, Bachus KN: Local and global subaxial cervical spine biomechanics after single-level fusion or cervical arthroplasty. Eur Spine J 18:1520-1527, 2009

10. Gertzbein SD, Robbins SE: Accuracy of pedicular screw placement in vivo. Spine (Phila Pa 1976) 15:11-14, 1990

11. Ghiselli G, Wang JC, Bhatia NN, Hsu WK, Dawson EG: Adjacent segment degeneration in the lumbar spine. J Bone Joint Surg Am 86-a:1497-1503, 2004

12. Gurr KR, McAfee PC, Warden KE, Shih CM: Roentgenographic and biomechanical analysis of lumbar fusions: a canine model. J Orthop Res 7:838-848, 1989

13. Henderson CM, Hennessy RG, Shuey HM, Jr., Shackelford EG: Posterior-lateral foraminotomy as an exclusive operative technique for cervical radiculopathy: a review of 846 consecutively operated cases. Neurosurgery 13:504-512, 1983 
14. Hilibrand AS, Carlson GD, Palumbo MA, Jones PK, Bohlman $\mathrm{HH}$ : Radiculopathy and myelopathy at segments adjacent to the site of a previous anterior cervical arthrodesis. J Bone Joint Surg Am 81:519-528, 1999

15. Hung CW, Wu MF, Hong RT, Weng MJ, Yu GF, Kao CH: Comparison of multifidus muscle atrophy after posterior lumbar interbody fusion with conventional and cortical bone trajectory. Clin Neurol Neurosurg 145:41-45, 2016

16. Kanayama M, Cunningham BW, Sefter JC, Goldstein JA, Stewart G, Kaneda K, et al.: Does spinal instrumentation influence the healing process of posterolateral spinal fusion? An in vivo animal model. Spine (Phila Pa 1976) 24:1058-1065, 1999

17. Kim SC, Kang SW, Kim SH, Cho KH, Kim SH: Clinical and radiological outcomes of anterior cervical interbody fusion using hydroxyapatite spacer. J Korean Neurosurg Soc 46:300-304, 2009

18. Laine T, Lund T, Ylikoski M, Lohikoski J, Schlenzka D: Accuracy of pedicle screw insertion with and without computer assistance: a randomised controlled clinical study in 100 consecutive patients. Eur Spine J 9:235-240, 2000

19. Lunsford LD, Bissonette DJ, Jannetta PJ, Sheptak PE, Zorub DS: Anterior surgery for cervical disc disease. Part 1: Treatment of lateral cervical disc herniation in 253 cases. J Neurosurg 53: 1-11, 1980

20. Masevnin S, Ptashnikov D, Michaylov D, Meng H, Smekalenkov $\mathrm{O}$, Zaborovskii $\mathrm{N}$ : Risk factors for adjacent segment disease development after lumbar fusion. Asian Spine J 9:239-244, 2015

21. Matsukawa K, Kato T, Yato Y, Sasao H, Imabayashi H, Hosogane $\mathrm{N}$, et al.: Incidence and risk factors of adjacent cranial facet joint violation following pedicle screw insertion using cortical bone trajectory technique. Spine (Phila Pa 1976) 41:E851-
E856, 2016

22. Mizuno M, Kuraishi K, Umeda Y, Sano T, Tsuji M, Suzuki H: Midline lumbar fusion with cortical bone trajectory screw. Neurol Med Chir (Tokyo) 54:716-721, 2014

23. Park P, Garton HJ, Gala VC, Hoff JT, McGillicuddy JE: Adjacent segment disease after lumbar or lumbosacral fusion: review of the literature. Spine (Phila Pa 1976) 29:1938-1944, 2004

24. Phan K, Hogan J, Maharaj M, Mobbs RJ: Cortical bone trajectory for lumbar pedicle screw placement: a review of published reports. Orthop Surg 7:213-221, 2015

25. Saavedra-Pozo FM, Deusdara RA, Benzel EC: Adjacent segment disease perspective and review of the literature. Ochsner J 14:78-83, 2014

26. Sakaura H, Miwa T, Yamashita T, Kuroda Y, Ohwada T: Fixation strength of caudal pedicle screws after posterior lumbar interbody fusion with the modified cortical bone trajectory screw method. Asian Spine J 10:639-645, 2016

27. Santoni BG, Hynes RA, McGilvray KC, Rodriguez-Canessa G, Lyons AS, Henson MA, et al.: Cortical bone trajectory for lumbar pedicle screws. Spine J 9:366-373, 2009

28. Snyder LA, Martinez-Del-Campo E, Neal MT, Zaidi HA, Awad AW, Bina R, et al.: Lumbar spinal fixation with cortical bone trajectory pedicle screws in 79 patients with degenerative disease: perioperative outcomes and complications. World Neurosurg 88:205-213, 2016

29. Wittenberg RH, Shea M, Swartz DE, Lee KS, White AA, 3rd, Hayes WC: Importance of bone mineral density in instrumented spine fusions. Spine (Phila Pa 1976) 16:647-652, 1991

30. Zdeblick TA: A prospective, randomized study of lumbar fusion. Preliminary results. Spine (Phila Pa 1976) 18:983-991, 1993 